Em Raimundo Lúlio fica evidente uma intensa vivacidade, admirável força e um privilegiado intelecto, que são frutos de um compromisso existencial. Assim, seguro de suas decisões, Lúlio é tomado por um agir próprio de um homem que agarra com severa autenticidade todas as mudanças existenciais de sua vida, sendo, pois, reformado por um novo modo de entregar-se à sua existência. A este modo, chamamos de conversão.

Lúlio estabelece um diálogo entre as diferentes formas de credo, fundamentando-se na razão, eximindo-se de qualquer argumento baseado nas autoridades religiosas, em suas revelações ou tradições. 0 Doutor lluminado considera apenas as razões necessárias e universais, afim de estabelecer algo validamente aceito pelas mesmas religiões e, sendo assim, procura um caminho que possa levar com segurança ao conhecimento de Deus que transcenda quaisquer interpretações humanas movidas pela cultura, tradição ou mesmo pelo sentimento religioso.

Lúlio constrói seu pensamento baseado num sistema exclusivamente racional na busca da Verdade sobre questões que sempre indagaram o ser humano: qual o sentido de sua existência, se possui uma essência própria, sua origem e seu fim, o Bem e o Mal, como direcionar o seu agir e sua relação com o Transcendente.

Raimundo Lúlio demonstra que o diálogo inter-religioso só é possível quando cada parte envolvida colocar a sua fé "entre parênteses". Os argumentos não devem ser baseados no fideísmo ou na autoridade religiosa, mas devem ser exclusivamente racionais. Como afirma o filósofo medieval Raimundo Lúlio (Ramón Llull): "o homem foi feito mais para entender do que para acreditar".

\section{CONTEXTO HISTÓRICO}

Até o início do século XIII, a Catalunha era dominada por árabes. Em 1229, o Rei Jaime I conquista a Ilha de Maiorca. Os árabes e judeus foram feitos escravos e as terras foram divididas pelo monarca entre seus oficiais do exército.

Em 1232, nasce Raimundo Lúlio em Maiorca, Reino de Aragão, atual Catalunha, proveniente de uma família abastada. Lúlio, em sua adolescêcia, atua como preceptor do Príncipe Jaime, filho de Jaime I. Posteriormente, Raimundo Lúlio torna-se senescal do filho do monarca.

Aos 23 anos, o catalão contrai matrimônio com Blanca Picany. Destas núpcias nascem os seus filhos: Madalena e Domingos.

Raimundo Lúlio, em meados de 1263, passa por uma intensa crise espiritual, seguida de uma fervorosa conversão. Lúlio se prepara intelectualmente e espiritualmente. Em seguida, afirma ter visto qual o seu destino ao se encontrar com a aparição mística do Cristo crucificado: doar toda sua vida à conversão dos infiéis e a propagação da fé católica, assumindo todo sacrifício inerente à sua escolha: o martírio. Neste mesmo contexto, veste o hábito de penitente.

Já na fase adulta, entre sua terceira e quarta décadas de vida, o filósofo adquire um escravo sarraceno para ensinar-lhe o idioma árabe .Nesta mesma época (1274-1264), inicia seus estudos na filosofia árabe e na filosofia judaica, sintetizando-as com a escolástica medieval. Este labor durou cerca de dez anos. Deste modo inicia, então, sua produção literária: "O Livro das Contemplações" e "O Livro do gentio e dos três Sábios".

Num contexto em que a coesão social era mantida em função da religião, sendo fundamental pertencer ao cristianismo e às suas estruturas administrativas, a conquista de território se dava pois, pela religião e não pelo nascimento. Contudo, em Maiorca era diferente. Esta região da península ibérica, era constituída por cristãos, mulçumanos e judeus, embora estes dois últimos não usufruíam dos mesmos direitos da comunidade cristã.

Lúlio partia da premissa que, quantos bens seriam alcançados se todos os homens compartilhassem de uma só fé, uma só religião, ao passo que é notável os inúmeros males que se originam pela pluralidade da fé e pela relativização da verdade:

Pensai, senhores, disse o sábio a seus companheiros, quantos são os danos que se originam pelo fato de os homens não seguirem uma só fé e uma só religião, e quantos são os bens que adviriam se todos tivessem uma só fé e uma só lei'.

Em seus argumentos, não tomava como referencial a autoridade dos homens considerados santos, mas as razões necessárias, as quais nenhuma autoridade por maior que fosse poderia ser contrária. Para Raimundo Lúlio, os argumentos de autoridade podem usar-se da retórica, tomar diversas formas, conduzir a um entendimento ambíguo e confuso, multiplicar as opiniões e afastar ainda mais da verdade:

Muitos argumentos de autoridade dos homens santos poder-seiam aplicar aos que apresentamos. Todavia, como nenhuma verdadeira autoridade pode ir contra as razões necessárias, (...) até mesmo porque os argumentos de autoridade podem ser expostos de diversas maneiras e se podem ter deles diversas opiniões, o que multiplica as palavras e o entendimento entra em confusão, quando os homens disputam entre si baseados em argumentos de autoridade ${ }^{2}$.

O filósofo maiorquio afirmava que há uma unidade entre a paz, a justiça e a verdade, de modo que nenhuma delas pode existir sem a outra. Para tanto, procurava uma base racional suficientemente sólida para provar as verdades provenientes da fé cristã, com o método conhecido como "Arte".

Ele estava crente de que o pensamento de Aristóteles já não mais fornecia concretude ao que tange às demonstrações desprovidas de argumentos fideístas sobre as verdades da Revelação. Deste modo, sente-se impelido em levar à conversão as outras denominações de crenças, tomando como subterfúgio uma ciência universal com princípios que possibilitam explicar toda a realidade, levando em consideração, de modo completo, toda a grandeza e nobreza de Deus, contando

1. Lúlio apud Jaulent 2001, p.13.

2. Lúlio 2002, p.131. 
com a produção e a atividade encontradas dentro Dele, ou dito de outro modo, a Trindade.

\section{CONTEXTO HISTÓRICO-FILOSÓFICO}

No período em que Lúlio viveu, Aristóteles era a maior autoridade pagã usada em conformidade com a Filosofia Cristã para explicar as realidades divinas.

Aristóteles em seu empenho de explicar a realidade das coisa descobriu a teoria do ato e da potência. Estes dois princípios, tomados conjuntamente, explicam a realidade de todas as substâncias primeiras, que são unidades de realidade, isto é, de ser. Ele, seguramente influenciado pelo seu mestre Platão, denominou de substâncias segundas às ideias universais das substâncias primeiras. Devido também à importância dessa influência platônica, nunca conseguiu extrair toda a força de sua teoria do ato e da potência, e por esse motivo não chegou a conceber o que seria uma Realidade Suprema, superior a todas as substâncias primeiras.

Lúlio foi o único pensador que completou a descoberta aristotélica do ato e da potência, atribuindo o Ato Puro à realidade suprema de Deus. Entendia o sábio catalão que o sistema de pensamento aristotélico não seria capaz de explicar plenamente a Realidade Suprema. Esta não consistia só numa atividade, como afirmava Aristóteles, mas num Ato puro, ou seja, algo ôntico e não só ético: um único Ser com um conteúdo infinito de atos, todos eles distintos, mas que unidos são o Ato puro e completo de Deus.

É verdade que entre os dois filósofos, deve situar-se Santo Tomás de Aquino, contemporâneo de Lúlio, que também atribuiu a Deus a condição de Ato puro; mas o aquinate não desenvolveu plenamente a teoria do ato ao aplicá-la a Deus e, influído poro Aristóteles, embora tivesse antes cristianizado seu pensamento, aplicou a Deus a teoria aristotélica da substância primeira. Esta última era para o grego uma unidade ativa de ser, e essa foi a perspectiva adotada por Santo Tomás: Deus é o Ato puro de ser. O conteúdo ativo e diversificado desse Ato Puro de Ser seria desenvolvido por Raimundo Lúlio. Embora seja de muita importância a contraposição do pensamento de Lúlio com o de Santo Tomás, o artigo manterá sua proposta em demonstrar exclusivamente o pensamento luliano para não permitir desvios.

\section{“O LIVRO DO GENTIO E OS TRÊS SÁBIOS"}

Raimundo Lúlio, já no século XIII defendia o diálogo inter-religioso que deve conter em si liberdade religiosa e uma livre expressão de pensamentos contraditórios entre si. Em sua obra O gentio e os três sábios, Lúlio sugere um diálogo sob os moldes acima descritos.

O livro começa com um gentio, um profundo filósofo, ateu, que tem um vasto conhecimento sobre muitas coisas, contudo desconhece a Deus e a ressurreição. Este desconhecimento leva-o a uma severa depressão, pois para ele, ao findar sua existência retornará ao nada e nunca mais poderá contemplar coisa nenhuma.
É conduzido, por meio desta crise depressiva a adentrar-se em uma floresta, repleta de fontes, belas árvores e paisagens para que ao contemplá-las, possa encontrar alívio pra sua dor. Contudo, esta dor só aumenta, pois para ele, ao morrer nunca mais poderá deleitar-se com o que outrora lhe trouxera tanto prazer.

Concomitantemente, na saída de uma cidade, encontram-se três sábios: um judeu, um muçulmano e um cristão. Estes saudaram-se e resolveram caminhar juntos e conversarem sobre o que ensinavam em suas crenças e ciências. Ao longo de seus percursos chegaram a uma fonte que irrigava cinco árvores. Estas mesmas àrvores possuem inúmeras flores que simbolizam os princípios constituintes da realidade , de modo que ao concordarem ou discordarem entre si, poderão, pois, fornecer as razões necessárias, bem como as condições de argumentação.

Dirigindo-se a elas, avistaram uma belíssima mulher, com vestimentas de nobres, montada num belo cavalo que bebia da água da fonte. Esta mulher apresentou-Ihes como sendo "Inteligência", Esta dama é uma alegoria utilizada por Raimundo Lúlio fazendo uma alusão a de que forma deve ser conduzido o diálogo inter-religioso, ou seja, por argumentos lógicos e racionais, isentos de quaisquer justificativas fideístas.

A demonstração da existência de Deus se dará por um discurso realizado pelos três sábios, de modo a não se poder identificar quem esta proferindo-o, se é o judeu, o cristão ou o sarraceno, visto que as a existência de Deus, Suas virtudes e a ressurreição são comuns às três religiões.

Lúlio usa da alegoria das árvores e das flores para explanar através da lógica as realidades divinas. Jaulent faz uma exposição sobre o significado das flores, ora citadas:

Lúlio usa aqui da alegoria. As árvores e as flores condessam um valor poético que consolará o gentio e aquietará as ânsias religiosas dos três sábios. As flores, dependendo das árvores, onde estiverem, representam a consideração conjunta de dois elementos de três grupos de realidades: as virtudes divinas, as virtudes humanas criadas, e os vícios. As argumentações do Livro do gentio e dos três sábios baseiam-se todas elas nas considerações que os sábios farão sobre as duas realidades que integram cada flor, sempre respeitando as condições que a Dama Inteligência irá definir ${ }^{3}$.

As flores das respectivas árvores têm como função representar o método lógico luliano. Segundo Jaulent, podemos resumi-las em número de dez:

1. Reconhecer e atribuir a Deus sempre a maior nobreza a essência, nas virtudes e nas obras.

2. É impossível que as virtudes divinas sejam contrárias umas às outras, nem uma menos que as demais.

3. As virtudes criadas têm que ser necessariamente maiores e mais nobres na medida em que mais fortemente signifiquem e demonstrem a grande nobreza das virtudes divinas ou incriadas.

3. Lúlio 2002, p.45. 
4. Jamais poderão existir contradições entre as virtudes incriadas e criadas.

5. Os vícios nunca poderão concordar com as virtudes de Deus.

6. É conveniente afirmar tudo, que por meio dos vícios, as virtudes de Deus são melhor significadas ao intelecto humano. Sendo assim, convém negar tudo aquilo que for antagônico à maior significação anteriormente citada, e também tudo quanto possibilite a diminuição das contrariedades entre as virtudes, Deus, e os vícios humanos, com excessão das condições das outras árvores.

7. De todas as virtudes criadas, é necessário que não hajam contradições entre si.

8. Aquilo que for mais conveniente para os homens serem mais virtuosos e terem maior mérito, através das virtudes criadas, tem de ser, em consequência, verdadeiro. Em contrapartida, o oposto, falso; salvando-se as condições das outras árvores.

9. Os vícios, sob hipótese alguma, podem concordar com as virtudes criadas.

10. As virtudes criadas mais contrárias aos vícios sejam as mais amáveis, e os vícios que são mais contrários às virtudes sejam os mais odiosos.

O Doutor lluminado usa-se destas condições para que o intelecto humano possa compreender as verdades do cristianismo, principalmente a Trindade e a encarnação. Jaulent, cita o seguinte exemplo para ilustrar a forma usada por Lúlio para atingir seu intento: Deus, por possuir poder infinito, poderia com este poder autodestruir-se? Segundo a condição de número " 2 " isto seria impossível, pois esta autodestruição seria contraditória à sua infinita bondade.

Podemos também concluir que é próprio do Ser Infinito não ter princípio, assim como lhe é próprio não ter fim, logo é uma conclusão tautológica e necessária admitir que o Infinito não pode findar a si mesmo. Seria uma contradição lógica do princípio de identidade.

Com estes argumentos, Raimundo Lúlio ao longo do livro irá demonstrar que Deus existe, Suas sete virtudes, as quais são representadas nas flores da primeira árvore e a esperança na ressurreição.

Depois que os três sábios terminam a sua exposição, o gentio enchese de alegria e júbilo por compreender que existe um Deus e que a vida não termina com a morte,ou seja, há a ressurreição. Emocionado, coloca os joelhos em terra e adora o Deus único, ressentido apenos por não tê-Lo conhecido antes. Desta forma, sentindo-se renovado por ter atingido certezas tão nobres, solicita aos sábios que o ensine como levar estas verdades às outra pessoas que ainda permanecem na obscuridade que até então ele se encontrava. Todavia, ao descobrir que os sábios professam três leis diferentes, o horror toma conta de sua alma a ponto de dizer que a angústia que se encontra agora, é maior da que outrora sentia por ignorar a existência de Deus e da vida eterna:
Ah, senhores! Em quão grande alegria e esperança me havieis colocado! Mas agora me fizestes retornar a muito maior ira e dor

do que costumava estar, porque depois depois de minha morte não tinha temor em sustentar trabalhos infinitos. Mas agora estou certo de que se não estiver no caminho verdadeiro, toda pena está já pronta, para atormentar perenemente a minha alma depois de minha morte! Ah, senhores! E que ventura é esta de me haver tirado de tão grande erro em que estava a minha alma? E por que a minha alma retornou a dores muito mais graves que as primeiras? ${ }^{4}$

É neste momento que os três sábios, diante do desepero do gentio, decidem separadamente, sob argumentos puramente racionais, guiados pela dama Inteligência, os artigos de suas respectivas crenças. Cada sábio, defenderá sua respectiva religião valendo-se da Ars luliana.

Lúlio começará por descrever o discurso argumentativo de cada sábio, os quais o farão sem a sustentação da Revelação.

Para tanto, fica estabelecido como uma norma básica que somente o gentio poderá interromper ou perguntar ao sábio que estiver discursando.

Ora, decidem que a ordem da exposição dos argumentos se dará de acordo com a antiguidade das fés profeçadas, sendo, pois, primeiramente o judeu com oito artigos de fé; o cristão, com quatorze e por fim, o muçulmano, com doze artigos.

Ao término das três exposições, o gentio poderá ter os subsídios necessários para poder escolher com clareza a crença pela qual irá decidir.

Após as exclamações dirigidas a Deus, o gentio quis contar aos três sábios qual foi a escolha por ele feita, ou seja, a qual religião decidira converter-se. Entretanto surpreendentemente, os sábios preferiram não escutá-lo, pois cada um acredita que ele escolheu à sua religião. Em seguida, se despediram do gentio e seguindo pelo caminho começaram a conversar como é ideal e necessário que todos tivessem apenas uma fé e uma forma de servir a Deus. E como vários conflitos seriam evitados se houvesse uma única crença:

E assim, como temos um Deus, um Criador, um Senhor, tomara tivéssemos uma só fé, uma só lei, uma única seita, uma só maneira de amar e honrar a Deus e fossemos amantes e ajudantes uns dos outros, e entre nós não houvesse nenhuma diferença e contrariedades. Agora, uns são inimigos dos outros e guerreiam e se matam, e somos uns cativos dos outros; e por tal guerra e morte e servidão são impedidos o louvor, a reverência e a honra que devemos dar a Deus todos os dias de nossa vida 5 .

O diálogo inter-religioso deve ser amparado pela liberdade das consciências em todos os aspectos por ele tratado; o conhecimento sobre a religião que compõe a outra parte do processo dialógico é outro elemento fundamental. 
A primeira finalidade é um saudável convívio com os indivíduos das outras religiões, bem como o conhecimento da outra crença visando uma possibilidade de se escolher entre continuar no credo a que a pessoa se encontrava, escolher por mudar ou abster-se de qualquer crença. Outra finalidade é uma proximidade física, a qual levará a uma dismistificação, que tem como consequência a derrubada dos preconceitos que se impõem como um obstáculo para o diálogo e o convívio. Isto levará a uma diminuição do ódio, da rivalização, das violências físicas e psíquicas, podendo as partes se reconhecerem muito mais como semelhantes do que como diferentes.

Um outro fator é que pelo fato do sujeito buscar argumentos para defender a sua fé, isto leva-o a um maior engajamento teórico e prático sobre a sua doutrina, o que possibilitará uma maior convicção. Conhecendo mais sobre a seu credo e tendo contato com o de outro, isto levará a um conhecimento comparativo da razão da existência ou da não existência de partes de uma ou de outra doutrina, demonstrando, assim, o valor do todo.

Se por um lado, Lúlio exalta o uso da razão nas disputas filosóficasteológicas, o Doutor lluminado sob hipótese alguma negligencia o valor da fé, colocando-a como subalterna à razão. Se assim fosse, inevitavelmente cairia num racionalismo exarcebado, contradizendo um dos pilares do cristianismo que é a fé como dom de Deus. À Filosofia, cabe o caráter especulativo, enquanto que a fé, ilumina o intelecto e conduz ao encontro da Verdade. Nisso, Lúlio será bem taxativo ao afirmar que a Verdade se manifesta de modo pleno na Encarnação do Verbo e no Mistério da Santíssima Trindade. Sendo assim, cabe a etmologia da palavra "Filosofia" como "amor à Sabedoria" ou mesmo "amor à Verdade".

Lúlio afirmava que para entender é necessário amar e para amar é necessário entender. A busca pelo conhecimento é, pois, um movimento recíproco entre amar e compreender. De modo simplificado, não é possível amar verdadeiramente aquilo que não se conhece e, tampouco conhecer auilo que não se ama.

O sujeito que se coloca no empreendimento de buscar a verdade, de querer conhecer, já está no caminho do bem. A Verdade é um bem em si, mas a busca por ela, enquanto atividade filosófica amparada pelo dom da fé, também é um bem. Se é natural do homem conhecer (e mais do que isso, é natural um "querer conhecer" - ato de vontade), é na adequação do intelecto aos objetos do conhecimento que o indivíduo tem seu conhecimento formulado de modo fidedigno, fugindo de uma interpretação subjetiva da realidade. E quanto mais se conhece a natureza das coisas criadas, por analogia, mais se conhece o Criador. Com efeito, o conhecimento para Lúlio era objetivo e aliado à fé, não permitindo ao sujeito uma interpretação individual, mas necessária e universal que culminava para o Doutor lluminado na impossibilidade de crer em qualquer fé que não fosse a cristã.

O homem ao se deparar com sua finitude e com sua insignificância existencial e, a partir daí, irá ao encontro das Verdades Transcendentais na tentativa de dar-lhe sentido à vida e preencher suas diversas indagações que nem mesmo a ciência e suas explicações positivas dão conta.
Mas se Lúlio não exclui a fé no processo epistemológico, também não lhe dá primazia em detrimento à razão, pois isso conduziria a um fideísmo e a um sectarismo tão combatidos pelo autor de $\mathrm{O}$ gentio e os três sábios. Não se pode ter a crença pela crença, a crença no absurdo, mas ter uma estrutura que dê sustentáculo à fé. Esses sustentáculo é a filosofia. A fé defende a Filosofia, pois precisa dela: tem necessidade dela porque é a Filosofia que interroga e busca a Verdade. A fé é o começo, o princípio e é a filosofia que permite dar continuidade a esse processo.

O catalão afirmava que entre a fé e a razão havia um movimento de reciprocidade em que uma sustentava a outra intrinsecamente. É o crer aliado ao compreender. Lúlio parte das verdades de fé e é a partir dela que, no seu sistema lógico, prova que não é absurda a fé cristã, mas conciliável à razão através das demonstrações como das árvores e flores. Lúlio concilia fé e razão, conciliando Deus e homem, diminuindo a distância entre o princípio e fim e unindo teologia e filosofia, atribuindo a elas a mesma origem divina.

Lúlio tratava a relação de fé e razão como uma metáfora dos degraus de uma escada em que ora a fé, ora a razão vão sucessivamente sustendando uma a outra. O primeiro degrau é a fé, o segundo a razão e, assim, segue-se essa subida. É o movimento das asas de um pássaro ao alçar voo, como afirma o Papa Emérito Bento XVI (Joseph Ratzinger) em sua encíclia Fides et Ratio. Uma asa seria a razão e a outra a fé. O voo só é possível quando as duas asas baterem juntas. É próprio do ser humano crer e compreender. Amar aquilo que se crê e crer naquilo que se ama. 
- ABELARDO. Diálogo entre un filósofo, un judío y un cristiano. (ed. bilingue).Buenos

- Aires: Losada, 2003.

- AQUINO, Tomás de. Onze Lições Sobre a Virtude. Comentário ao Segundo Livro da Ética de Aristóteles. Trad. Tiago Tondinelli. São Paulo: Ecclesiae, 2014. . Suma Teológica - Volume IV. Trad. Carlos Josaphat Pinto de Oliveira . São Paulo: Edições Loyola, 2005. Suma Teológica - Volume V. Trad. Carlos Josaphat Pinto de Oliveira. São Paulo: Edições Loyola, 2005.

. Suma Teológica - Volume VI. Trad. Carlos Josaphat Pinto de Oliveira. São Paulo: Edições Loyola, 2005. . Suma Contra os Gentios. Trad. D. Odilão Moura, OSB. São Paulo: Ecclesiae, 2017.

- ARISTÓTELES. De Anima. São Paulo: Editora 34, 2006.

- ARISTÓTELES. Metafísica. [Tradução Giovanni Reale] São Paulo: Loyola, 2002.

- BOEHNER, P.; GILSON, E. História da Filosofia Cristã. Trad. Raimundo Vier. Petrópolis: Editora Vozes, 1970.

- COSTA, Ricardo da. "Muçulmanos e Cristãos nos diálogos de Ramon Llull (1232-

- 1316)". Anales del Seminario de Historia de la Filosofía, Vol. 19 (2002): 67-96.

- DE LIBERA, Alain. A Filosofia Medieval. Trad. Nicolás Nyimi Campanário e Yvone Maria de Campos Teixeira da Silva. São Paulo: Edições Loyola, 2011.

- FIDORA, Alexander. Ramon Llull frente a la crítica actual al diálogo inter-religioso: El Arte luliana como propuesta para una "Filosofia de las religiones". Revista Española

- de Filosofía Medieval, 10 (2003), pp. 227-243.

- HALEVI, Yehuda. El Cuzary. Barcelona: Ediciones Índigo, 2001.

- JAULENT, Esteve. O esse na ética de Raimundo Lúlio. Veritas. Porto Alegre. v. 40. nº 159. p. 599-621. 1995.

- LLULL, Ramon. O Livro das Bestas. Trad. Ricardo da Costa. São Paulo: Editora Escala, 2004.

- _ _ O Livro do Amigo e do Amado. Trad. Luiz Carlos Bombassaro.São Paulo: Editora Escala, 2004.

$\bullet$ . O Livro do Gentio e Dos Três Sábios.Trad. Esteve Jaulent. Rio de Janeiro: Editora Vozes, 2001.

$\bullet$ O Livro dos Mil Provérbios. Trad. Ricardo da Costa. São Paulo: Editora Escala, 2006.

Escritos Antiaverroístas (1309-1311). Trad. Brasília Bernadete, Sérgio Alcides e Ronald Polito. Porto Alegre: EDIPUCRS, 2001.

- MAIMONIDES, Moses. Dalalat al-Hairin/ The Guide for the Perplexed. Tradução do

- original árabe por M. Friedlander. NY: Dover Publications, 1956.

- MARTINS, Mário. Uma síntese da "Ars Generalis" de Raimundo Lulio, em versos Goliardos. Revista portuguesa de filosofia. Braga, Tomo XXXIV, p. 59-68. Janeiro/março de 1978.

- PRING-MILL, Robert. El Microcosmos Lul.lià. Maiorca: Editorial Moll, 2006.

- RATZINGER, Joseph. Fé, verdade, tolerância - O cristianismo e as grandes religiões do mundo - Tradução Sivar Hoeppner Ferreira . São Paulo: Instituto Brasileiro de Filosofia e Ciência "Raimundo Lúlio" (Ramon Llull), 2007.

- REALE, Giovani \& ANTISERI, Dario. História da filosofia - Antigüidade e Idade Média. v. 1. 2 ed. São Paulo: Paulus. 1990. (Coleção Filosofia) 
- SARANYANA, Josep-Ignasi. A Filosofia Medieval. (das origens patrísticas à escolástica barroca). Trad. Fernando Salles. São Paulo: Instituto Brasileiro de Filosofia e Ciência "Raimundo Lúlio", 2006.

- SIMON, Josep Maria Ruiz. A Arte de Raimundo Lúlio e a Teoria Escolástica. São Paulo: Instituto Brasileiro de Filosofia e Ciência "Raimundo Lúlio" (Ramon Llull), 2004.

- SUAU, Teodor. Ramon Llull, somni, miracle i misteri. Barcelona: Publicacions de l'Abadia de Montserrat, 2014.

- SVENSON, Manfred. Abelardo. "El argumento del diálogo entre un filósofo, un judio y un cristiano". Revista Philosophica, 137, Vol. 32 [Semestre II / 2007] Valparaíso. p. 137- 155.

- TROYES, Chrétien. Perceval ou O Romance do Graal. Trad. Rosemary Costhek Abilio. São Paulo: Martins Fontes, 2002.

- VEIGA, Bernardo. É impossível o diálogo inter-religioso?: O pensamento de Bento XVI e a visão de Raimundo Lúlio sobre o diálogo interreligioso. São Paulo: Instituto Brasileiro de Filosofia e Ciência "Raimundo Lúlio" (Ramon Llull), 2008. 